\title{
Effects of Nitric Oxide Scavengers on Thermoinhibition of Seed Germination in Arabidopsis thaliana ${ }^{1}$
}

\author{
K. K. Hossain ${ }^{a}$, R. D. Itoh ${ }^{a}$, G. Yoshimura ${ }^{a}$, G. Tokuda ${ }^{b}$, H. Oku ${ }^{b}$, \\ M. F. Cohen ${ }^{c}$, and H. Yamasaki ${ }^{a}$ \\ ${ }^{a}$ Faculty of Science, University of the Ryukyus, Nishihara, Okinawa, 903-0213 Japan; \\ fax: +81-98-895-8576; e-mail: yamasaki@sci.u-ryukyu.ac.jp \\ ${ }^{b}$ Center of Molecular Biosciences (COMB), University of the Ryukyus, Nishihara, Okinawa, 903-0213 Japan \\ ${ }^{c}$ Department of Biology, Sonoma State University, 1801 E. Cotati Ave., Rohnert Park California, 94928 USA
}

Received December 19, 2008

\begin{abstract}
Plant seeds sometimes do not germinate at elevated temperature. The thermoinhibition mechanisms of seed germination have yet not revealed. Here we describe a chemical approach to improve seed germination at high temperature. We compared the temperature response of germination between wild-type Arabidopsis thaliana and its T-DNA insertion mutant $\triangle$ AtGLB3 that lacks a functional gene encoding GLB3, a homologue of bacterial truncated $\mathrm{Hb}(\operatorname{trHb})$. Under optimal temperature conditions (e.g. $\left.22^{\circ} \mathrm{C}\right)$, the seeds of $\triangle \mathrm{AtGLB} 3$ and the wild type germinated at a frequency near $100 \%$. In contrast, at $32^{\circ} \mathrm{C}$ the seeds of $\triangle$ AtGLB3 did not germinate while wild-type seeds retained the same high germination frequency. The germination of $\triangle \mathrm{AtGLB} 3$ at $32^{\circ} \mathrm{C}$ was partially restored by supplementation with the nitric oxide-specific scavenger 2-(4-carboxyphenyl)-4,4,5,5-tetramethylimidazoline-1-oxyl-3-oxide (carboxy-PTIO; cPTIO), 3-(3,4-dihydroxycinnamoyl)quinic acid, bovine serum $\mathrm{Hb}$, or isoprene. The results presented in this study suggest that chemical scavengers for reactive nitrogen species potentially improve seed germination at high temperature.
\end{abstract}

Key words: Arabidopsis thaliana - germination - hemoglobin - high temperature - nitric oxide

DOI: $10.1134 / \mathrm{S} 1021443710020093$

\section{INTRODUCTION}

Plant growth and development are highly affected by ambient temperature. Temperatures beyond the growth optimum, either higher or lower, potentially harm plants by acting as environmental stressors [1]. High temperature, heat or thermal stress, inhibits plant growth through the disturbance of cellular functions and often results in death of the entire plant. One of the puzzling questions about the heat stress response is why cellular dysfunction occurs even far below the temperature of protein denaturing. In certain plants and also in coral-algal symbiotic systems, in fact, a temperature increase by only several degrees causes growth inhibition and is sometimes lethal. Until recently, many factors have been reported to improve plant heat tolerance: heat shock proteins (HSPs), lipids, acetylcholine, glycinebetaine, and antioxidant enzymes. However, the fundamental

\footnotetext{
${ }^{1}$ This text was submitted by the authors in English.

Abbreviations: CGA-chlorogenic acid; cPTIO-2-(4-carboxyphenyl)-4,4,5,5-tetramethylimidazoline-1-oxyl-3-oxide; $\mathrm{Hb}-$ hemoglobin; HSP-heat-shock protein; MS - Murashige and Skoog nutrient medium; NOS - NO synthase; RNS - reactive nitrogen species; $\mathrm{SNP}$ — sodium nitroprusside.
}

mechanism for the action of heat stress on plants remains obscure. In the context of global warming, the issue has become more important than before because many endemic species may face extinction due to elevated ambient temperatures. The coral bleaching phenomenon, which can be ascribed to disruption of the symbiotic photosynthesis due to an increase in surface water temperature, is a well known impact of global warming [2]. In addition to such impacts on natural ecosystems, agriculture has also been influenced by global warming. There are many heat-sensitive vegetables, and their vegetated areas are declining, raising a potential risk of food crises worldwide. Thus, evaluation of heat stress response is now a big scientific issue as well as a strong social demand. In this study we focused on the heat tolerance capacity of seed germination.

It is well known that germination depends on many environmental factors, such as water or light. Temperature is also an important factor for seed germination. Optimum temperature varies among species, and there is a temperature limit for seed germination [3]. However, there is no consensus idea to account for the heat tolerance of seed germination. Recent studies 
have suggested that nitric oxide (NO) is involved in the process of germination [4]. NO is a gaseous free radical that had long been known as a harmful air pollutant produced thorough the combustion of fossil fuels [5]. Numerous studies have suggested that NO is an essential molecule in diverse physiological processes in plants: growth, pathogen response, flowering, senescence, stomata movements, and photosynthesis. Although it is evident that NO plays a crucial role in plants, its production mechanism as well as the signal reception system for NO are yet a big mystery [5].

Since the finding that sodium nitroprusside (SNP) stimulates seed germination of common chickweed [6], many studies using chemical NO donors have shown that NO is required to break seed dormancy in arabidopsis [7], barley [7], tomato [8], and other plant species. Here we describe effects of NO scavengers on arabidopsis seed germination. The results presented in this study show that the chemical scavengers for NO are capable of improving germination at high temperatures. Aiming to integrate of different aspects, we discuss a cause of heat stress damage to plant cells in terms of a balance between beneficial and harmful effects of NO.

\section{MATERIALS AND METHODS}

Plant material. Arabidopsis thaliana $\triangle$ AtGLB3 seeds (SALK_060213; Columbia (Col-0) background) were generously provided by Dr. Joseph Ecker (The Salk Institute for Biological Studies, United States) through Arabidopsis Biological Resource Center (ABRC, United States).

Germination assay. The wild type and $\triangle$ AtGLB3 seeds were sterilized at room temperature by soaking for $10 \mathrm{~min}$ in $70 \%(\mathrm{v} / \mathrm{v})$ ethanol followed by incubation in a solution containing $2 \%(\mathrm{v} / \mathrm{v})$ hypochloric acid and $0.02 \%(\mathrm{w} / \mathrm{v})$ Tween 20 for $5 \mathrm{~min}$. After removing the solution, all seeds were washed thoroughly with sterile distilled water five times. Seeds (30 per plate) were germinated on 0.5-strength Murashige and Skoog (MS) medium (pH 5.7) supplemented with $0.8 \%$ agar, $2 \%(\mathrm{w} / \mathrm{v})$ sucrose, and vitamins. The agar plates were placed in growth chambers to observe germination with a $16 / 8$ h $50 \mu \mathrm{E} /\left(\mathrm{m}^{2} \mathrm{~s}\right)$ day/night cycle at various temperatures $(17,22,27$, 32,37 , or $42^{\circ} \mathrm{C}$ ).

For germination experiments with natural soil, the wild type and $\triangle$ AtGLB3 seeds (30 per plate) were placed into petri plates containing $45 \mathrm{~g}$ of soil and were incubated at 22 or $32^{\circ} \mathrm{C}$ under a $16 / 8 \mathrm{~h}$ day/night cycle.

Chemical treatments. $100 \mu 1$ of $5 \mathrm{mM}$ 2-(4-carboxyphenyl)-4,4,5,5-tetramethylimidazoline-1-oxyl-3-oxide (cPTIO) was used as a specific NO scavenger [9]. Either $5 \mathrm{mM}$ chlorogenic acid (CGA) or $0.5 \mathrm{mM}$ bovine $\mathrm{Hb}$ was added onto the agar plate prior to plac- ing seeds. In natural soil experiments, $100 \mu 1$ of $5 \mathrm{mM}$ cPTIO was added onto the soil plate prior to placing seeds. cPTIO, CGA, and bovine $\mathrm{Hb}$ were dissolved in distilled water. Isoprene is a highly volatile compound. We made a hole at the center of the agar plates, and isoprene was added onto the hole prior to placing seeds. The plates were sealed with parafilm. All the solutions were prepared freshly, immediately before use.

Detection of gaseous NO and isoprene. Gaseous NO and isoprene were quantified by the chemiluminescence method. When ozone $\left(\mathrm{O}_{3}\right)$ reacts with either $\mathrm{NO}$ or isoprene, luminescence is emitted due to this reaction. We used a NOA-280i nitric oxide analyzer (Sievers Instruments, Inc. Boulder, United States) and an mBA1000 real-time isoprene analyzer (Taiyo Instruments Inc. Osaka, Japan). The isoprene/ozone reaction produces electronically excited formaldehyde, whose subsequent chemiluminescence is monitored with a blue-sensitive photomultiplier tube. Gaseous NO was quantified using a similar principle [10].

For chemical treatment experiments, pure standard gases were used: NO gas $(0.6 \mathrm{ppm})$ and isoprene gas applied either as isoprene liquid or pure standard gas (17.52 ppm). To obtain isoprene gas from liquid, we injected $10 \mu \mathrm{l}$ of liquid isoprene (Nacalai tesque, Japan) into a 500-ml caped flask. The reaction was carried out within a caped flask $(500 \mathrm{ml})$. We filled the volume with $0.6 \mathrm{ppm}$ of $\mathrm{NO}$ gas and measured NO concentration with the nitric oxide analyzer. After confirming the measurement, isoprene gas $(100 \mu \mathrm{l})$ was injected and the mixed gas was incubated for $5 \mathrm{~min}$ at a room temperature $\left(25^{\circ} \mathrm{C}\right)$. NO concentration was measured with the nitric oxide analyzer after the reaction. The identical experiments were conducted with the real-time isoprene analyzer for the quantification of isoprene gas concentration before and after the reaction.

\section{RESULTS}

\section{$\triangle A t G L B 3$ Is Sensitive to High Temperature}

A. thaliana possesses three types of hemoglobins (Hbs), i.e., AtGLB1, AtGLB2, and AtGLB3. Among them, AtGLB3 is a homologue of bacterial trHb [11], and its physiological function remains unknown. Recent studies have suggested that the nonsymbiotic Hbs may be involved in the regulation of NO rather than oxygen transport [12]. $\triangle$ AtGLB3 is a mutant that lacks functional AtGLB3 (data not shown).

We compared seed germination between the wild type and $\triangle$ AtGLB3. Figure 1 shows the frequency of seed germination after 5-day incubation at different temperatures. In the wild type, germination was inhibited by incubation temperatures higher than $30^{\circ} \mathrm{C}$. Even at $37^{\circ} \mathrm{C}$, however, $20 \%$ of the wild-type seeds germinated. Seed germination of $\triangle$ AtGLB3 was sensitive to temperatures approximately $5^{\circ} \mathrm{C}$ less than the 
wild type (Fig. 1). At lower temperatures (17, 22, and $27^{\circ} \mathrm{C}$ ), the wild type and $\triangle$ AtGLB3 both showed nearly $100 \%$ germination. In contrast, $\triangle$ AtGLB3 showed no germination at $32^{\circ} \mathrm{C}$, whereas $90 \%$ of wildtype seeds still germinated. At $42^{\circ} \mathrm{C}$, both types of seeds could not germinate.

One may consider that a long exposure of seeds to high temperature is lethal. To check mortality of the seeds after their incubation at high temperature, we compared seed germination by transferring the seeds to an optimum temperature after high-temperature treatment. The seeds of $\triangle \mathrm{AtGLB} 3$ and the wild type were incubated at $32^{\circ} \mathrm{C}$ for 6 days, and then they were incubated at $25^{\circ} \mathrm{C}$ for another 10 days. After up to 4 day-long incubation at $32^{\circ} \mathrm{C}$, no substantial effect was observed in $\triangle$ AtGLB3 germination (table). Further incubation ( 5 and 6 days) at $32^{\circ} \mathrm{C}$ showed less germination of $\triangle \mathrm{AtGLB} 3$ seeds even after their transfer to the temperature of $25^{\circ} \mathrm{C}$. These results suggest that germination of $\triangle \mathrm{AtGLB} 3$ is sensitive to high temperature.

\section{Restoration of Seed Germination by NO Scavengers}

Figure 2 shows time courses of seed germination in the wild type and $\triangle$ AtGLB3. There was no substantial difference between them at $22^{\circ} \mathrm{C}$; even faster germination was observed in $\triangle \mathrm{AtGLB} 3$. However, the mutant showed no germination at $32^{\circ} \mathrm{C}$, where the wild type seeds still showed $100 \%$ germination. In the bacterium Mycobacterium tuberculosis, the expression of trHb has been demonstrated to increase its tolerance against the host innate immune response through increased NOscavenging activity [13]. We hypothesized that the failure of $\triangle \mathrm{AtGLB} 3$ to germinate at $32^{\circ} \mathrm{C}$ was associated with a low NO-removing capability. If this were the case, supplemental chemicals that can destroy NO should be able to restore the germination of $\triangle$ AtGLB3 at $32^{\circ} \mathrm{C}$. To test this hypothesis, we pretreated the $\triangle$ AtGLB3 seeds with 2-(4-carboxyphenyl)-4,4,5,5tetrametylimidazoline-1-oxyl-3-oxide (cPTIO), an NO scavenger. In fact, cPTIO partially restored germination $(40 \%)$ at $32^{\circ} \mathrm{C}$ (Figs. 3a, 3b), strongly suggesting the involvement of $\mathrm{NO}$ in the heat tolerance.

\section{Effect of CGA and Bovine Hb on Seed Germination}

Chlorogenic acid (CGA) is a plant secondary metabolite that is a potent antioxidant for scavenging of ROS and reactive nitrogen species (RNS) [14]. Bovine $\mathrm{Hb}$ also has been used as an NO quencher for in vitro experiments [15]. We tested effects of these compounds on germination in $\triangle$ AtGLB3. As we expected, both CGA and bovine $\mathrm{Hb}$ were effective to restore germination of $\triangle \mathrm{AtGLB} 3$ at $32^{\circ} \mathrm{C}$ (Figs. 3c, 3d). The mutant seeds pretreated with CGA and bovine $\mathrm{Hb}$ showed 45 and $60 \%$ germination at $32^{\circ} \mathrm{C}$ after 7 days, respectively.

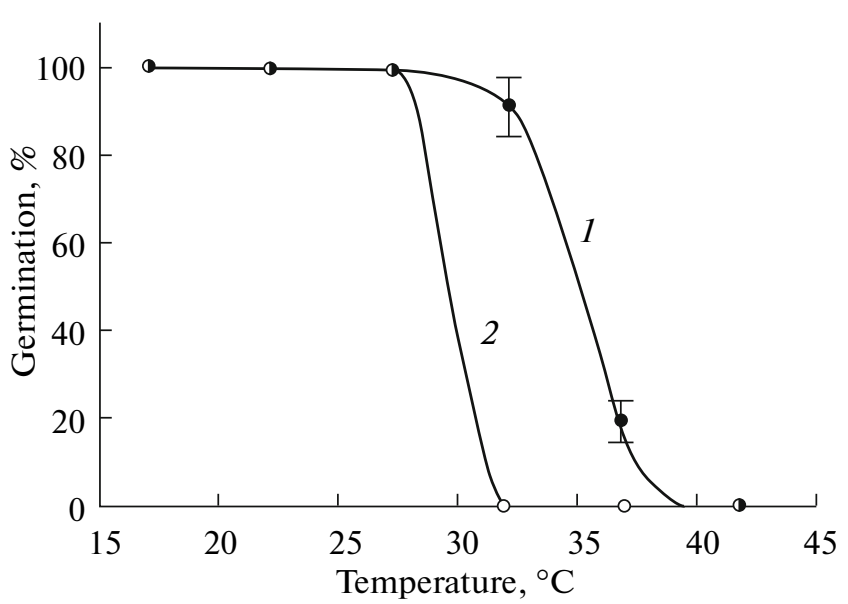

Fig. 1. Temperature dependence of seed germination in the wild type and $\triangle \mathrm{AtGLB} 3$.

Each plot represents germination after 5 days. Each point is average value for 30 seeds. Error bars show standard error of the mean of three independent experiments.

(1) Wild type; (2) $\triangle$ AtGLB3.

\section{Germination in Natural Soil}

We verified the above results by testing seed germination capability under natural soil conditions (Fig. 4). At $22^{\circ} \mathrm{C}$, again, the both types of seeds showed $100 \%$ germination. $\triangle$ AtGLB3 displayed faster germination than the wild type (Fig. 4a). As similar to the results presented in Fig. 2, germination of $\triangle$ AtGLB3 was severely suppressed at $32^{\circ} \mathrm{C}$ (Fig. 4b). Supplementation of cPTIO remarkably restored germination observed at $32^{\circ} \mathrm{C}$ (Fig. 4c). These results essentially agree with those obtained in the experiments with agar plates (Figs. 2, 3).

\section{Effects of Isoprene on Seed Germination}

In further experiments, we investigated effects of isoprene that may improve plant heat tolerance [16]. Isoprene (2-methyl-1,3-butadiene) is a major bio-

Effects of preincubation at $32^{\circ} \mathrm{C}$ on germination at $25^{\circ} \mathrm{C}$

\begin{tabular}{c|c|c}
\hline \multirow{2}{*}{$\begin{array}{c}\text { Days of pretreatment } \\
\text { at } 32^{\circ} \mathrm{C}\end{array}$} & \multicolumn{2}{|c}{$\begin{array}{c}\text { Germination after } 10 \text { days } \\
\text { at } 25^{\circ} \mathrm{C}, \%\end{array}$} \\
\cline { 2 - 3 } & wild type & $\Delta$ AtGLB3 \\
\hline 1 & $100 \pm 0$ & $100 \pm 0$ \\
2 & $100 \pm 0$ & $100 \pm 0$ \\
3 & $100 \pm 0$ & $80 \pm 2$ \\
4 & $100 \pm 0$ & $80 \pm 2$ \\
5 & $90 \pm 2$ & $55 \pm 4$ \\
6 & $90 \pm 2$ & $25 \pm 2$ \\
\hline
\end{tabular}

Notes: Each point is average value for 30 seeds. Experimental conditions were similar to those with MS medium in Fig. 1. Data are means $\pm \mathrm{SE}$ of independent three replicates. 

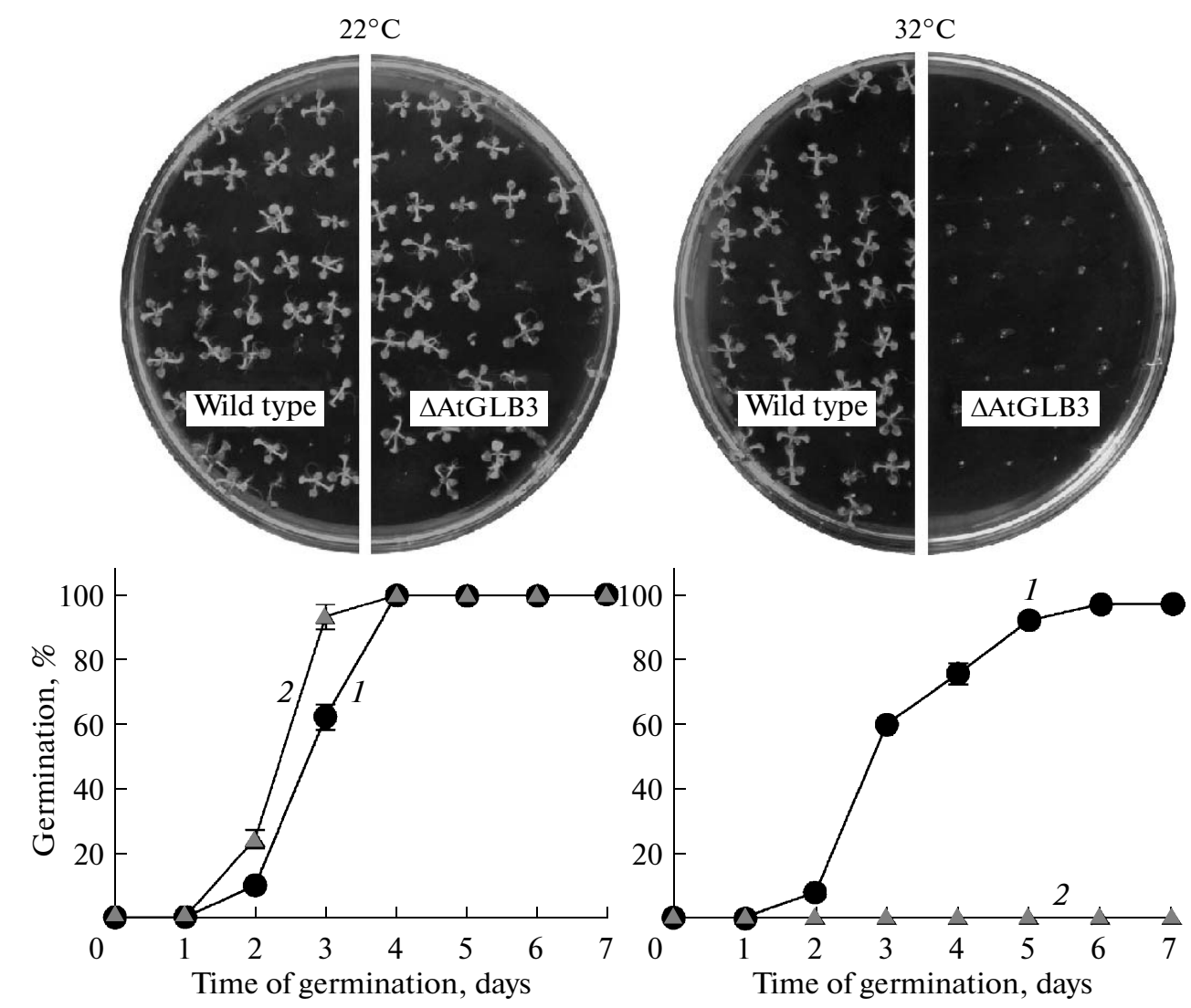

Fig. 2. Inhibition of $\triangle A t G L B 3$ germination at high temperature.

Top photographs show seedlings on the 7th day of germination. Bottom graphs show time courses for the germination in the (1) wild type and (2) $\triangle \mathrm{AtGLB} 3$ observed at $22^{\circ} \mathrm{C}$ and $32^{\circ} \mathrm{C}$. Each point is average value for 30 seeds. Error bars show standard error of the mean of three independent experiments.

genic volatile organic compound that is abundantly emitted by plants. Recently, isoprene has been reported to play a signaling role under stress conditions by modulating the level of $\mathrm{NO}$ as well as various ROS [17]. This led us to consider that isoprene may also restore germination of $\triangle \mathrm{AtGLB} 3$ seeds. Figure 5 shows the restoration effect of isoprene on the germination of $\triangle A t G L B 3$ seeds at high temperature. The seeds were incubated with different amounts $(0.2,2$, 20 , and $200 \mu \mathrm{l}$ ) of liquid isoprene at $32^{\circ} \mathrm{C}$. After 7 days of incubation, the wild type showed less germination than normal, whereas $\triangle \mathrm{AtGLB} 3$ showed $52 \%$ germination in the $20 \mu \mathrm{l}$ isoprene treatments. The supplement with $2 \mu \mathrm{l}$ of isoprene also stimulated $\triangle$ AtGLB3 seed germination as similar to $20 \mu \mathrm{l}$ (data not shown). The lower or higher concentration of isoprene did not show such restoration effects on seed germination. Unlike the treatments with the RNS scavengers described above, the morphology of developed leaves and roots changed; coloration of leaves appeared yellowish-green, and the sizes of leaves and roots were smaller than normal ones. In addition to the positive restoration effect on the mutant, it seems that the iso- prene treatment includes a negative effect on the development as well.

\section{Chemical Reactivity of NO with Isoprene}

The results presented in Fig. 5 showed that isoprene was capable of restoring germination at high temperature. Isoprene might be able to scavenge NO directly [17]. To test this possibility, we examined the chemical reactivity between isoprene and NO. Figure 6a shows change in the concentration of NO after the addition of isoprene. We used pure NO gas (standard gas adjusted to $663 \mathrm{ppm}$ with $\mathrm{N}_{2}$ ) and liquid isoprene. Liquid isoprene is highly volatile, and it readily becomes an isoprene gas. We monitored the concentration of gaseous NO by the chemiluminescence method. As shown in Fig. 6a, the addition of isoprene to the NO gas did not change the concentration of the latter. The results of Fig. 6a clearly indicate that NO is not scavenged by isoprene. We further verified this by monitoring isoprene gas concentration. Figure $6 \mathrm{~b}$ shows the effect of NO on the concentration of isoprene gas. Because the detection of isoprene gas is also based on a similar principle, i.e., chemiluminescence 
(a)
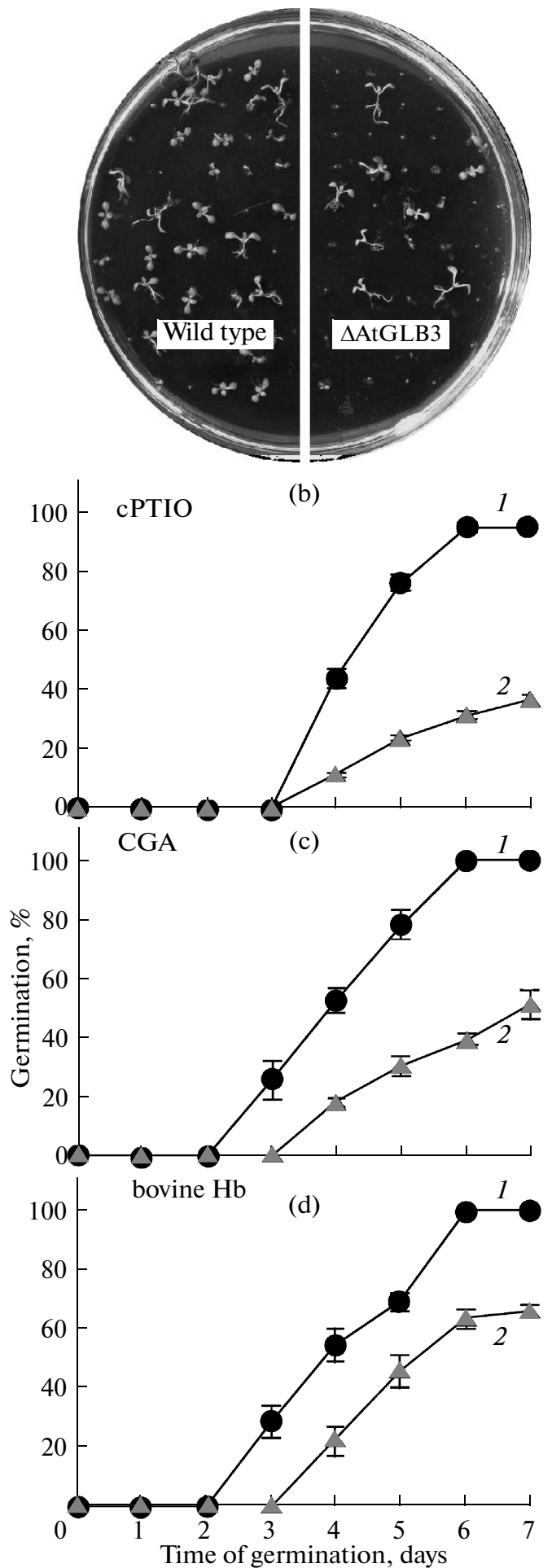

Fig. 3. Restoration of the $\triangle$ AtGLB3 germination by supplemented chemicals.

(a) Photograph of the seedlings on the 7th day of germination in the presence of the NO scavenger cPTIO $\left(32^{\circ} \mathrm{C}\right)$; time courses for wild type and $\triangle \mathrm{AtGLB} 3$ germination at $32^{\circ} \mathrm{C}$ in the presence of (b) cPTIO, (c) chlorogenic acid, (d) bovine hemoglobin. Each point is average value for 30 seeds. Error bars show standard error of the mean of three independent experiments. Other experimental conditions are similar to those in Fig. 2.

(1) Wild type; (2) $\triangle$ AtGLB3.
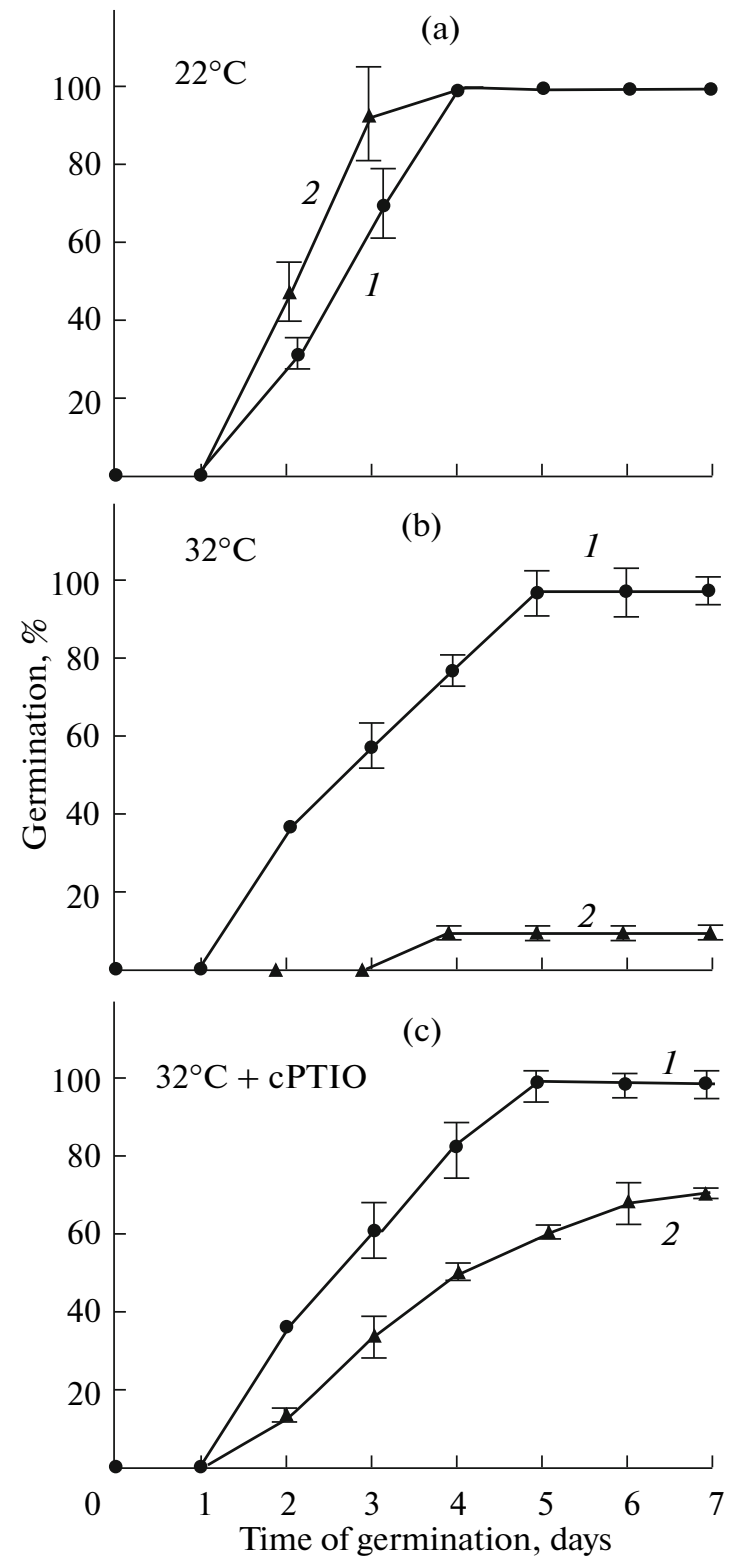

Fig. 4. Germination of $\triangle \mathrm{AtGLB} 3$ in natural soil.

(a) Time courses for the wild type and $\triangle \mathrm{AtGLB} 3$ germination at $22^{\circ} \mathrm{C}$ without cPTIO. (b) Germination at $32^{\circ} \mathrm{C}$ without cPTIO. (c) Germination at $32^{\circ} \mathrm{C}$ with cPTIO.

(1) Wild type; (2) $\triangle$ AtGLB3.

$5 \mathrm{mM}$ cPTIO solution $(100 \mu \mathrm{l})$ was added to the soil. Each point is average value for 30 seeds. Error bars show standard error of the mean of three independent experiments. Other experimental conditions are similar to those in Fig. 2.

technique, some of NO seemed to be counted as isoprene. It is important to note that concentration of isoprene gas also did not decrease even after mixing with NO gas (Fig. 6b), which implies that NO does not react directly with isoprene. The absence of the reactivity between $\mathrm{NO}$ and isoprene was further verified by GC-MS chromatography (data not shown). During the experiments, we noticed that contamination of air 

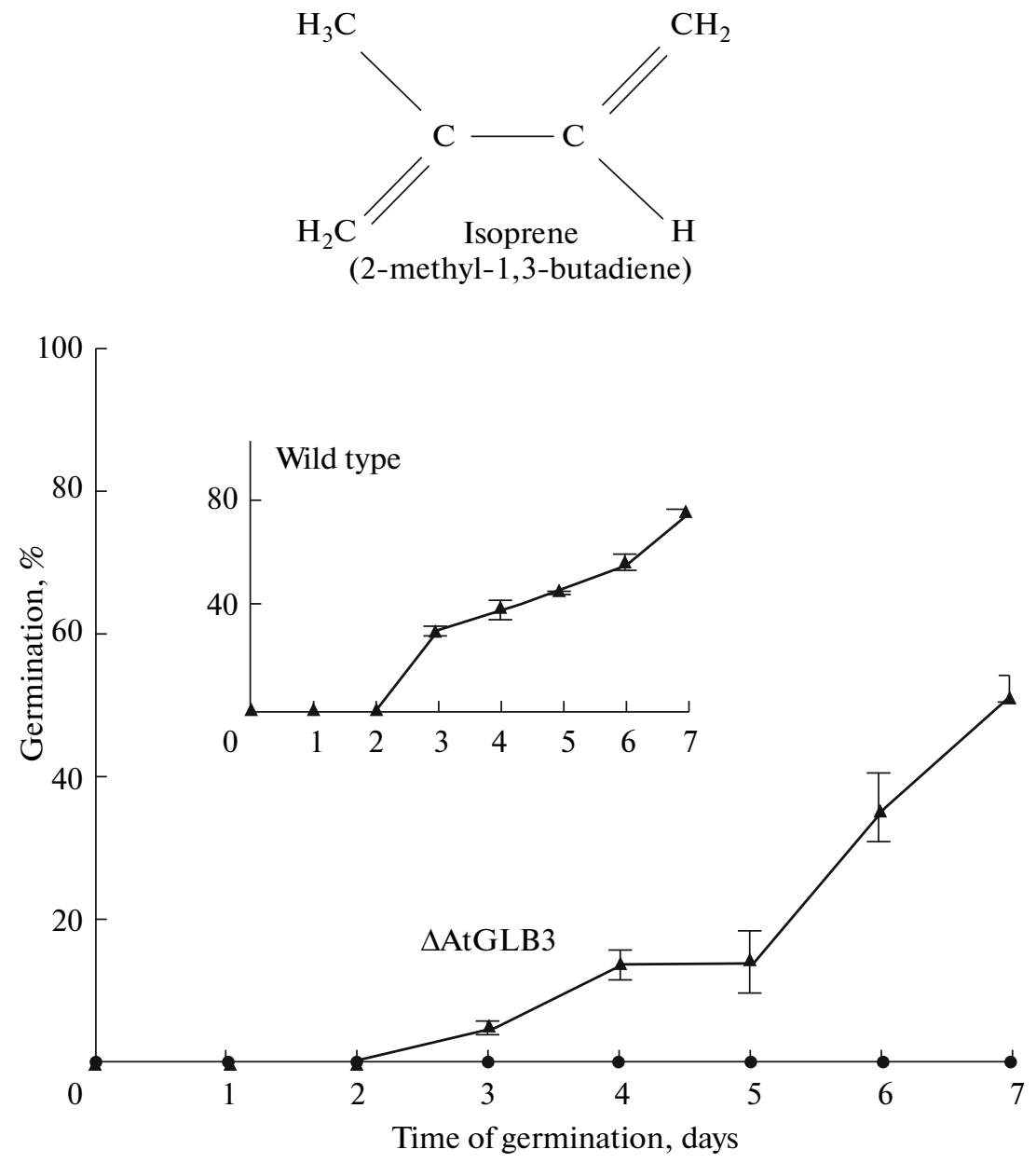

Fig. 5. Effects of isoprene on seed germination at high temperature.

Each point is average value for 30 seeds. The seeds were incubated at $32^{\circ} \mathrm{C}(\mathbf{\Delta})$ with or $(\bullet)$ without $20 \mu l$ of isoprene. Error bars show standard error of the mean of three independent experiments. Other experimental conditions are similar to those in Fig. 3. Chemical structure of isoprene is represented on the top.

resulted in isoprene decrease. Under ambient conditions, NO is easily oxidized and converted to toxic $\mathrm{NO}_{2}$. We speculated that isoprene would scavenge the oxidized product $\mathrm{NO}_{2}$ rather than $\mathrm{NO}$ itself. Figure 6c demonstrates such direct reaction between isoprene and $\mathrm{NO}_{2}$ gas. When liquid isoprene was added into a chamber filled with $\mathrm{NO}_{2}$ gas, brown coloration due to $\mathrm{NO}_{2}$ disappeared and its absorbance decreased. After the reaction, yellowish gel was produced (data not shown). As distinct from our previous knowledge, these results suggest that isoprene is capable of removing $\mathrm{NO}_{2}$ instead of $\mathrm{NO}$ scavenging.

\section{DISCUSSION}

\section{NO Scavengers as Anti-Thermoinhibition Agents}

The complementation of a lost capability by chemicals is an important finding in the present study; the heat-sensitive characteristic of $\triangle \mathrm{AtGLB} 3$ in germination can be compensated by supplemental chemicals.
Figure $3 \mathrm{~b}$ shows that $\mathrm{cPTIO}$, a chemical NO scavenger, can restore the germination ability of $\triangle \mathrm{AtGLB} 3$ at high temperature. Moreover, CGA also restores germination of $\triangle A t G L B 3$ (Fig. 3c). CGA is a potent phenolic antioxidant that is widely distributed over plant species in their leaves, fruits, and seeds. The phytophenolic can scavenge not only ROS, including superoxide $\left(\mathrm{O}_{2}^{-}\right)$, hydroxyl radicals $(\cdot \mathrm{OH})$, and hydrogen peroxide $\left(\mathrm{H}_{2} \mathrm{O}_{2}\right)$, but also RNS such as $\mathrm{NO}$ and peroxynitrite $\left(\mathrm{ONOO}^{-}\right)$[14]. It is interesting to note that bovine $\mathrm{Hb}$, structurally unrelated to CGA, shows a similar effect in the $\triangle$ AtGLB3 germination at high temperature (Figs. 3c, 3d). Although the primary physiological function of bovine $\mathrm{Hb}$ is $\mathrm{O}_{2}$ delivery in blood, it is also a strong quencher of NO by forming nitrosylhemoglobin. It appears that a potential to remove NO is a common feature over the three different chemicals, namely, cPTIO, CGA, and bovine $\mathrm{Hb}$. Therefore, we consider that these chemicals help promote germination at high temperature by removing 


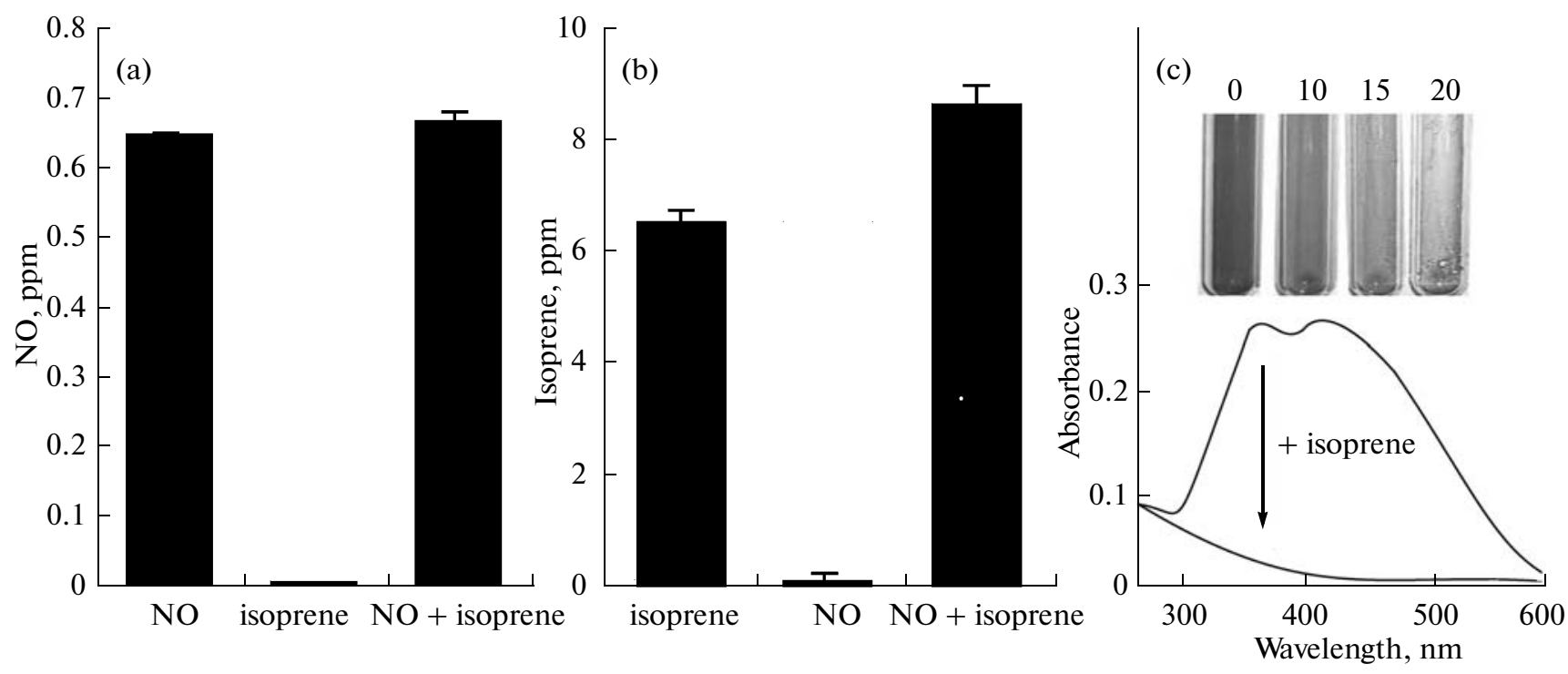

Fig. 6. Reactivity of NO with isoprene.

(a) Chemiluminescence measurements of NO gas. NO gas only (left); isoprene gas only (middle); NO gas plus isoprene (right).

(b) Chemiluminescence measurements of isoprene gas. Isoprene gas only (left); NO gas only (middle); isoprene gas plus NO gas

(right). (c) $\mathrm{NO}_{2}$ absorbance decrease by liquid isoprene. The inset photographs show coloration of $\mathrm{NO}_{2}$ in the presence of 0,10 ,

15 , and $20 \mu \mathrm{l}$ isoprene (from left to right).

excessive NO that could be produced within the seeds, a possible linkage between AtGLB3 and NO.

\section{Isoprene Effects}

Isoprene has been known for many years to be associated with plant heat tolerance especially in tree species, such as gum or pine trees. Interestingly that isoprene can also restore the $\triangle$ AtGLB3 seed germination at high temperature (Fig. 5). It should be noted that isoprene, at the concentrations used, worked positively on the germination of $\triangle$ AtGLB3, but it slightly inhibited the wild-type seed germination (Fig. 5, inset), which was equal to $100 \%$ even at high temperature $\left(32^{\circ} \mathrm{C}\right)$. Therefore, it is likely that isoprene can provide not only the restoration effect but also the inhibition of regular metabolism.

We had presumed that the restoration effect of isoprene could be ascribed to its NO-scavenging activity [17]. As shown in Fig. 6, however, isoprene did not scavenge pure $\mathrm{NO}$ gas. Instead, $\mathrm{NO}_{2}$, an oxidized product of NO, was scavenged by isoprene (Fig. 6c). These results of chemical experiments suggest that the mechanism for the restoration effect of isoprene differs from that of cPTIO, CGA, and bovine $\mathrm{Hb}$.

\section{Effects of NO on Seed Germination}

It is now widely accepted that NO plays pivotal roles in plants as a signaling molecule. Also, NO has been reported to participate in seed germination [4]. Many studies have shown that chemical NO donors, includ- ing SNP and $S$-nitroso- $N$-acetylpenicillamine, stimulate seed germination in lettuce (Lactuca sativa) [18], A. thaliana [7], and tomato (Lycopersicon esculentum) [8]. More recently, it was found that $\beta$-amylase activity, which is required for an early stage of seed germination, can be induced by SNP in many plant species: wheat, barley, soybean, rice, and watermelon [19]. Although some of the effects may be due not to NO but to cyanide or nitrate, these studies have supported the idea that NO production is a prerequisite for plant seed germination as a positive function of NO. One may consider that the results described in the present study are opposite to previous ones, i.e., a negative effect of NO on seed germination.

In addition to signaling functions of NO, it is also appreciated that NO sometimes exerts harmful effects on living systems as well as beneficial ones: high concentrations of $\mathrm{NO}$ are sometimes phytotoxic. We have reported that overproduction of NO strongly inhibits respiratory ATP synthesis in the mitochondria [20] and also inhibits photosynthetic activity [21]. These inhibitory actions are ascribed to the inhibition of redox enzymes as a direct effect of NO. In the presence of ROS, irreversible damage may occur through $\mathrm{ONOO}^{-}$formation. $\mathrm{ONOO}^{-}$, a reaction product between $\mathrm{NO}$ and $\mathrm{O}_{2}^{-}$, is the most toxic RNS that potentially causes cellular dysfunctions via DNA damage and protein nitration [14] or nitrosative stress. Thus, living organisms must strictly control NO level to tune a fine balance between the beneficial (signaling) and harmful (deleterious effect) actions of NO [5]. In this context, the internal concentration of $\mathrm{NO}$ 
must be regulated during germination; there should be an optimum range of $\mathrm{NO}$ concentration for each plant species [4]. As the sources of NO production in seeds, nitrate reductase (NR) and putative NO synthase (NOS)-like enzyme have been reported. Although cellular localization of NO production remains obscure, we consider it plausible that cPTIO, CGA, and bovine $\mathrm{Hb}$ scavenge $\mathrm{NO}$ outside the cells and keep internal NO level low enough to suppress negative effects, a possible explanation for the partial restoration of germination by the chemicals (Figs. 3, 4).

\section{Function of AtGLB3 in Seed Germination}

Recent investigations have confirmed that Hbs are distributed among eukaryotes and prokaryotes [22]. Land plants include GLB1, GLB2, and GLB3 and some bryophytes possess GLB0, an ancestor of GLB1 (GLB2) and GLB3 [22]. Many papers have proposed functions of these GLBs in plants. In contrast to GLB1 and GLB2, however, there have been a limited number of papers available on physiological function of GLB3 [12]. GLB3 is a homologue of bacterial trHb [11]. It has been reported that bacterial trHbs are not involved in oxygen delivery but involved in destruction of NO [23]. The failure of $\triangle A t G L B 3$ to germinate at high temperature can be accounted by a low NO-scavenging activity that may be partially complemented by the addition of exogenous NO scavengers (Figs. 3, 4). The findings of the present study imply that NO is involved in cellular dysfunction induced by high temperature stress. NO is potentially produced in plants and algae, and its lifetime would become longer at high temperature [24] or under anoxic conditions [12]. AtGLB3 may help germination at high temperature by removing NO that can be excessively produced under conditions of high temperature stress.

Since the discovery of nonsymbiotic $\mathrm{Hb}$ family, our recognition of the classical protein has changed, even in the case of vertebrate blood $\mathrm{Hb}$. Although endothelium NOS has been presumed to serve NO in the vascular system for vasorelaxation, the enzyme is not responsible under hypoxic or anoxic conditions when ischemia occurs. In principle, NOS cannot synthesize $\mathrm{NO}$ under ischemic conditions because it requires $\mathrm{O}_{2}$ to produce $\mathrm{NO}$ along with $\mathrm{L}$-arginine. Recently, blood $\mathrm{Hb}$ has been found to exhibit nitrite reductase (NiR) activity that catalyzes NO production using NADH and nitrite $\left(\mathrm{NO}_{2}^{-}\right)$as the substrates; apparently similar reaction to that of plant NR [25]. It seems that Hbs possess multiple functions to tune a fine balance among $\mathrm{O}_{2}, \mathrm{CO}_{2}, \mathrm{NO}$, and $\mathrm{H}_{2} \mathrm{~S}$ in the tissues. The recombinant proteins of AtGLBs show peroxidaselike activity, the results suggesting that the Hbs may function as $\mathrm{H}_{2} \mathrm{O}_{2}$-scavenging enzymes [26]. It has also been reported that these enzymes could mediate protein nitration when $\mathrm{NO}_{2}^{-}$is provided as a substrate. In addition to NO-scavenging function, we need to take these enzymatic features of GLBs into the consideration as a possible physiological role.

It should be emphasized that we have yet not obtained concrete evidence for the presence of a plant NO signaling system that is equivalent to the animal one. NO in plants may just serve as an intermediate in the synthesis of an unknown signaling molecule. This possibility is supported by the fact that $\mathrm{NO}_{2}^{-}, \mathrm{NO}_{3}^{-}$, and $\mathrm{NO}_{2}$ sometimes display similar effects to $\mathrm{NO}$ on many phenomena, including germination [4]. Although the present study has suggested the requirement of AtGLB3 for seed germination at high temperature, we feel it premature to conclude the occurrence of the NO-scavenging function of AtGLB3. The putative enzymatic property and biochemical function of AtGLB3 must await further investigation.

\section{Possible Linkage between NO and Heat Tolerance Mechanism}

On the mechanisms for plant heat-tolerance, various types of hypothesis have been proposed. In Arabidopsis plants, heat stress induces expression of multiple genes, and their induction results in enhanced heat tolerance. The expression of HSPs is one of the best characterized responses against heat stress. In addition to HSP expression, plants exposed to heat stress change membrane fatty acid composition and the rate of photosynthesis, and accumulate soluble organic compounds, such as proline. Although each factor has been proven to be involved in heat tolerance, none of them can sole account for heat tolerance of a whole plant under field conditions.

Isoprene emission has been reported as a heat stress response because the emission increases at high temperatures. Isoprene is simply a by-product of photosynthesis to dissipate excessively assimilated carbon under high temperature conditions. Isoprene has been also proposed as an antioxidant. The most widely accepted hypothesis came from Sharkey and Singsaas [16]. They have proposed that isoprene protects the photosynthetic apparatus from thermal damage by stabilizing the photosynthetic electron transport complexes embedded in the thylakoid membranes [16]. In fact, isoprene emission is closely linked with photosynthetic electron transport and light intensity. Our results (Fig. 6) have added a new issue to these arguments; does isoprene act as an $\mathrm{NO}_{2}$ scavenger to reduce NO toxicity? Although isoprene did not scavenge NO directly, as previously thought [17], we consider it plausible that $\mathrm{NO}_{2}$-scavenging reaction of isoprene contributes to lowering the toxicity of $\mathrm{NO}$ under in vivo conditions. The toxicity of NO itself is not so strong, but the reaction products $\mathrm{ONOO}^{-}$and $\mathrm{NO}_{2}$ are cytotoxic. Therefore, removing $\mathrm{NO}_{2}$ from the cells would be beneficial to reduce a risk of NO signaling 


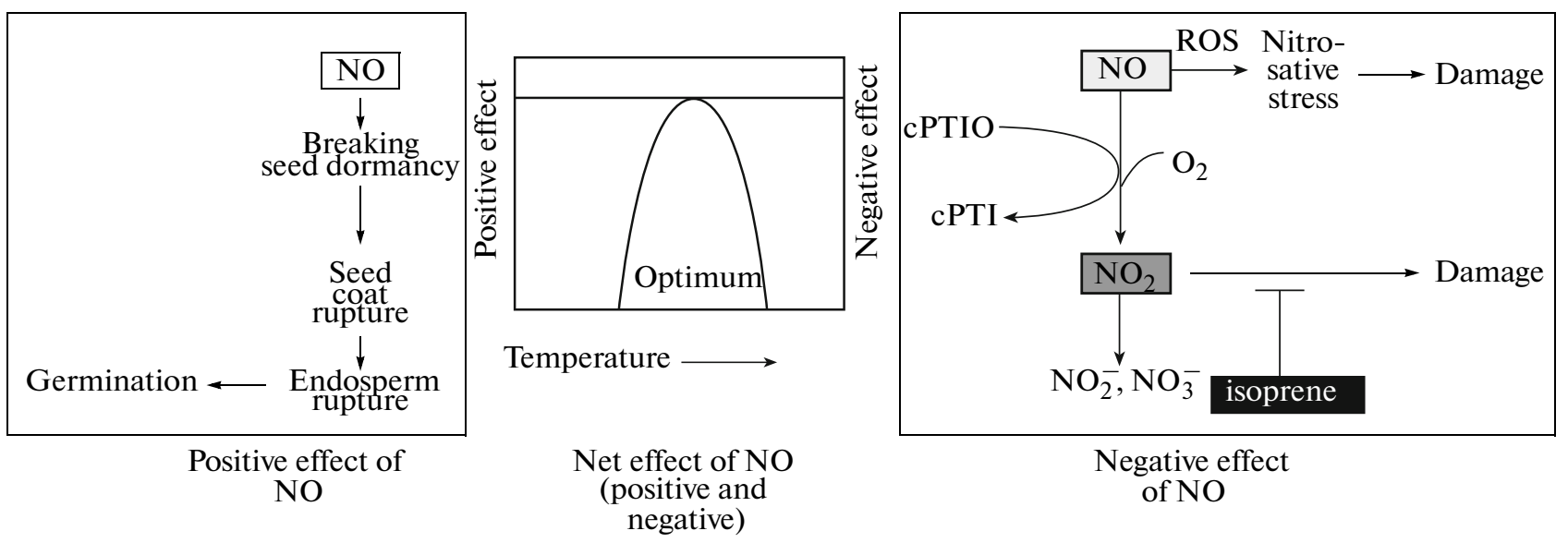

Fig. 7. A hypothetical scheme for dual effects of NO in germination.

NO is required for seed germination to break dormancy and to induce a range of enzymes (left panel). In addition to this positive effect, NO exerts deleterious effects through RNS production. In the presence of ROS, NO may turn to the toxic RNS ONOO and $\mathrm{NO}_{2}$ that potentially disturb cellular metabolisms by acting as nitrosative stress (right panel). The toxicity of RNS may increase under heat stress conditions. As the sum of positive and negative effects, a bell-shape curve could be drawn as a tolerance range against temperature (middle panel). For details see text.

system. Because NO is diffusive across the membranes and its oxidation may occur all over the cells, the contribution of NO-scavenging macromolecules, such as hemoglobins, must be limited. In contrast, gaseous and membrane permeable scavengers, such as isoprene, may be much more effective to intercept the gaseous toxins. Therefore, we suggest that isoprene functions as an anti-RNS agent to reduce a potential risk of possessing an NO signaling system.

\section{Balance between the Opposites}

Figure 7 illustrates a hypothetical scheme for the effects of $\mathrm{NO}$ on seed germination. NO is required for breaking dormancy [7]. It seems that endogenously produced or exogenously provided NO initiates germination metabolism, although the enzymes responsible for endogenous NO production have not been confirmed [18]. In the case of the NR enzyme, its "normal" nitrate-reducing activity is severely inhibited above $30^{\circ} \mathrm{C}$ and $\mathrm{ONOO}^{-}$production becomes significant instead [24]. This may be ascribed to the vulnerability of the redox domains of NR enzyme, and the conformational change would stimulate NO production. Interestingly, the reaction between $\mathrm{NO}$ and $\mathrm{O}_{2}$ to form $\mathrm{NO}_{2}$ depends negatively on temperature, suggesting that NO becomes much stable at a high temperature. In general, the respiration rate increases at high temperatures, resulting in stimulation of ROS production as well. Under such conditions, the production of RNS such as $\mathrm{ONOO}^{-}$and $\mathrm{NO}_{2}$, could be also increased. RNS causes nitrosylation and nitration of proteins and biomolecules, a situation referred as to nitrosative stress [27].

As seen in oxygen toxicity induced by ROS, NO exhibits a double-edged sword effect: beneficial and harmful actions exerted by a single molecule. Although NO is a prerequisite for germination, excessive NO would turn to harming plant cells. AtGLB3 may tune a fine balance between beneficial and harmful effects of NO, although the putative enzymatic feature of AtGLB3 is not fully understood. The chemicals cPTIO (Figs. 3, 4), CGA (Fig. 3c), bovine Hb (Fig. 3d), and isoprene (Fig. 5) may contribute in part to suppress the formation of RNS under heat stress conditions. We tried to detect NO production during germination by multiple techniques: chemiluminescence method, electrochemical method, and NO staining with the fluorescent NO probe DAF-2DA (data not shown). We could not obtain direct evidence to prove the release of $\mathrm{NO}$ either from the wild type or from $\triangle \mathrm{AtGLB} 3$ seeds. It is likely that the requirement of NO in vivo is a trace amount that may be beyond the detection limit.

Superimposing the positive effect on the negative one, we could draw a bell-shaped optimum range of $\mathrm{NO}$ as a function of temperature (Fig. 7). It is known that recommended depth for sowing seeds in the soils differs among plant species. Due to rhizosphere bacteria, especially nitrifying bacteria, $\mathrm{O}_{2}$ availability decreases with depth while NO concentrations may increase [4]. The scheme explains well such trends in terms of species-specific optimum NO concentration for seed germination. 


\section{ACKNOWLEDGMENTS}

This work was supported by the Grant-in-Aid for Scientific Research (B) to H.Y. and partly by the 21 st century COE program of the University of the Ryukyus from the Ministry of Education, Culture, Sports, Science, and Technology, Japan.

\section{REFERENCES}

1. Cohen, M.F., Mazzola, M., and Yamasaki, Y., Nitric Oxide Research in Agriculture: Bridging the Plant and Bacterial Realms, Abiotic Stress Tolerance in Plants, Rai, A.K. and Takabe, T., Eds., Berlin: Springer-Verlag, 2006, pp. 71-90.

2. Takahashi, S., Nakamura, T., Sakamizu, M., van Woesik, R., and Yamasaki, H., Repair Machinery of Symbiotic Photosynthesis as the Primary Target of Heat Stress for Reef-Building Corals, Plant Cell Physiol., 2004, vol. 45, pp. 251-255.

3. Cristaudo, A., Gresta, F., Luciani, F., and Restuccia, A., Effects of After-Harvest Period and Environmental Factors on Seed Dormancy of Amaranthus Species, Weed Res., 2007, vol. 47, pp. 327-334.

4. Giba, Z., Grubisic, D., and Konjevic, R., Seeking the Role of NO in Breaking Dormancy, Nitric Oxide in Plant Growth, Development and Stress Physiology, Lamattina, L. and Polaacco, J.C., Eds., Berlin: Springer-Verlag, 2007, pp. 91-111.

5. Yamasaki, H., Nitric Oxide Research in Plant Biology: Its Past and Future, Nitric Oxide Signalings in Higher Plants, Magalhaes, J.R., Singh, R.P., and Passos, L.P., Eds., LLC Houston, USA: Studium Press, 2004, pp. 1-23.

6. Giba, Z., Grubisic, D., and Konjevic, R., Sodium Nitroprusside-Stimulated Germination of Common Chick Weed (Stellaria media, L.) Seeds, Arch. Biol. Sci., 1992, vol. 44, pp. 17-18.

7. Bethke, P.C., Gubler, F., Jacobsen, J.V., and Jones, R.L., Dormancy of Arabidopsis Seeds and Barley Grains Can Be Broken by Nitric Oxide, Planta, 2004, vol. 219, pp. 847-855.

8. Correa-Aragunde, N., Graziano, M., and Lamattina, L., Nitric Oxide Plays a Central Role in Determining Lateral Root Development in Tomato, Planta, 2004, vol. 218, pp. 900-905.

9. Akaike, T., Yoshida, M., Miyamoto, Y., Sato, K., Kohno, M., Sasamoto, K., Miyazaki, K., Ueda, S., and Maeda, H., Antagonistic Action of Imidazolineoxyl NOxides against Endothelium-Derived Relaxing Factor/NO through a Radical Reaction, Biochemistry, 1993, vol. 32, pp. 827-832.

10. Arita, N.O., Cohen, M.F., Tokuda, G., and Yamasaki, H., Fluorometric Detection of Nitric Oxide with Diaminofluoresceins (DAFs): Application and Limitation for Plant NO Growth, Nitric Oxide in Plant Growth, Lamattina, L. and Polaacco, J.C., Eds., Berlin: Springer-Verlag, 2007, pp. 269-280.

11. Wittenberg, J.B., Bolognesi, M., and Wittenberg, B.A., Mechanisms of Cytoplasmic Hemoglobin and Myoglo- bin Function, Annu. Rev. Biophys. Chem., 1990, vol. 19, pp. 217-241.

12. Dordas, C., Rivoal, J., and Hill, R.D., Plant Hemoglobins, Nitric Oxide and Hypoxic Stress, Ann. Bot., 2003, vol. 91, pp. 173-178.

13. Pathania, R., Navani, N.K., Gardnen, A.M., Gardner, P.R., and Dikshit, K.L., Nitric Oxide Scavenging and Detoxification by the Mycobacterium tuberculosis Haemoglobin, $\mathrm{HbN}$ in Escherichia coli, Mol. Microbiol., 2002, vol. 45, pp. 1303-1314.

14. Sakihama, Y., Tamaki, R., Shimoji, H., Ichiba, T., Fukushi, Y., Tahara, S., and Yamasaki, H., Enzymatic Nitration of Phytophenolics: Evidence for Peroxynitrite-Independent Nitration of Plant Secondary Metabolites, FEBS Lett., 2003, vol. 553, pp. 377-380.

15. Yamasaki, H. and Sakihama, Y., Simultaneous Production of Nitric Oxide and Peroxynitrite by Plant Nitrate Reductase: In Vitro Evidence for the NR-Dependent Formation of Active Nitrogen Species, FEBS Lett., 2000, vol. 468, pp. 89-92.

16. Sharkey, T.D. and Singsaas, E.L., Why Plants Emit Isoprene, Nature, 1995, vol. 374, pp. 769-769.

17. Velikova, V., Pinelli, P., Pasqualini, S., Reale, L., Ferranti, F., and Loreto, F., Isoprene Decreases the Concentration of Nitric Oxide in Leaves Exposed to Elevated Ozone, New Phytol., 2005, vol. 166, pp. 419-426.

18. Beligni, M.V. and Lamattina, L., Nitric Oxide Stimulates Seed Germination and De-Etiolation, and Inhibits Hypocotyl Elongation, Three Light-Inducible Responses in Plants, Planta, 2000, vol. 210, pp. 215221.

19. Zhang, H., Shen, W.B., Zhang, W., and Xu, L.L., A Rapid Response of Beta-Amylase to Nitric Oxide but Not Gibberellin in Wheat Seeds during the Early Stage of Germination, Planta, 2005, vol. 220, pp. 708-716.

20. Yamasaki, H., Shimiji, H., Ohshiro, Y., and Sahihama, Y., Inhibitory Effects of Nitric Oxide on Oxidative Phosphorylation in Plant Mitochondria, Nitric Oxide Biol. Chem., 2001, vol. 5, pp. 261-270.

21. Takahashi, S. and Yamasaki, H., Reversible Inhibition of Photophosphorylation in Chloroplasts by Nitric Oxide, FEBS Lett., 2002, vol. 512, pp. 145-148.

22. Watts, R.A., Hunt, P.W., Hvitved, A.N., Hargrove, M.S., Peacock, W.J., and Dennis, E.S.A., Hemoglobin from Plants Homologous to Truncated Hemoglobins of Microorganisms, Proc. Natl. Acad. Sci. USA, 2001, vol. 98, pp. $10119-10124$.

23. Ouellett, H., Ouellett, Y., Richard, C., Labarre, M., Wittenberg, B., Wittenberg, J., and Guertin, M., Truncated Hemoglobin HbN Protects Mycobacterium bovis from Nitric Oxide, Proc. Natl. Acad. Sci. USA, 2002, vol. 99, pp. 5902-5907.

24. Yamasaki, H. and Sakihama, Y., Nitrate Reductase as a Producer of Nitric Oxide in Plants: TemperatureDependence of the Enzymatic Active Nitrogen Formation, PS2001 Proc. 12th Int. Congr. Photosynthesis CSIRO Publishing Collingwood, S21-003, 2001. 
25. Yamasaki, H., Sakihama, Y., and Takahashi, S., An Alternative Pathway for Nitric Oxide Production in Plants: New Features of an Old Enzyme, Trends Plant Sci., 1999, vol. 4, pp. 128-129.

26. Sakamoto, A., Sakurao, S., Fukunaga, K., Matsubara, T., Ueda-Hashimoto, M., Tsukamoto, S., Takahashi, M., and Morikawa, H., Three Distinct Arabidopsis Hemoglobin Exhibit Peroxidase-Like Activity
Differentially Mediate Nitrite-Dependent Protein Nitration, FEBS Lett., 2004, vol. 572, pp. 27-32.

27. Valderrama, R., Corpas, F.J., Carreras, A., FernándezOcaña, A., Chaki, M., Luque, F., GómezRodríguez, M.V., Colmenero-Varea, P., del Río, L.A., and Barroso, J.B., Nitrosative Stress in Plants, FEBS Lett., 2007, vol. 581, pp. 453-461. 